\title{
El yacimiento arqueológico de Lacipo (Casares, Málaga)
}

\author{
Pedro Rodríguez Oliva | Universidad de Málaga \\ URL de la contribución <www.iaph.es/revistaph/index.php/revistaph/article/view/3979>
}

\section{RESUMEN}

Presentamos aquí un estado de la cuestión sobre el yacimiento arqueológico que se localiza en el lugar llamado El Torreón, en el término municipal de Casares (Málaga), que se viene identificando con la ciudad romana de Lacipo en el Conventus Gaditanus y a la que citan Plinio el Viejo (Naturalis Historia, III, 15); Pomponio Mela (Chorographia, II, 94-95) y el geógrafo Ptolomeo (II, 4, 9). Enclavada sobre una colina que domina el valle del Guadiaro-Genal, sus restos arqueológicos eran conocidos de antiguo gracias al interés que despertaron desde el Renacimiento en algunos eruditos de Ronda y Sevilla. Entre aquellos vestigios destacan los de sus murallas, una serie de cisternas a las que llegaba el agua a través de un acueducto que arrancaba de la Sierra Crestellina y otros de algunos de sus edificios públicos. De sus momentos de apogeo destacan sus acuñaciones en bronce de época republicana así como una interesante serie de epígrafes latinos de época altoimperial. Parcialmente excavada en los años 1975 y 1976, de aquel lugar proceden una serie de materiales arqueológicos que se guardan y exponen en el Museo de Málaga. De su importancia aún a mediados del siglo III d. C. nos habla la inscripción que lleva el pedestal marmóreo de una estatua hallado y conservado en Córdoba que estuvo dedicada a Marco Valerio Saturnino, un lacipponensis que fue flamen de la provincia Baetica (Corpus Inscriptionum Latinarum -en adelante CIL- II2/7, 259).

\section{Palabras clave}

Bética | Casares (Málaga) | Ciudades | Costa del Sol | Lacipo | Roma | Yacimientos arqueológicos | 


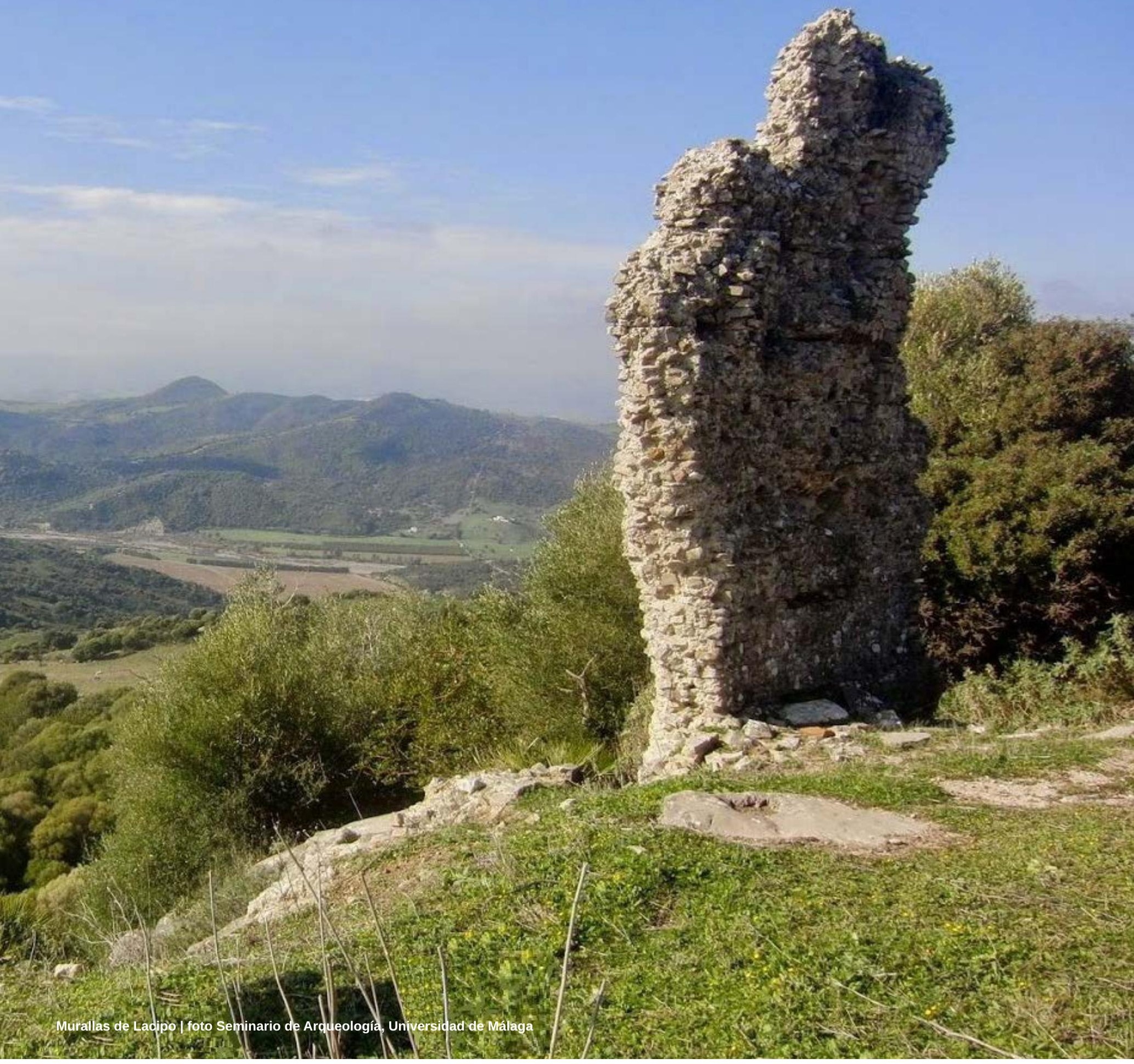


En el decreto 59/1996 de 6 de febrero de la Consejería de Cultura de la Junta de Andalucía por el que los restos de la ciudad romana de Lacipo fueron declarados Bien de Interés Cultural con la categoría de zona arqueológica, se destacaba con acierto que aquel yacimiento arqueológico del término municipal de Casares (Málaga) presenta como elemento destacable de su topografía un emplazamiento en altura y una "situación estratégica... que dominaría la vía de penetración del valle hacia el interior de las actuales provincias de Cádiz y Málaga" (DECRETO 59/1996). Efectivamente, las ruinas de esa ciudad antigua se localizan sobre un monte de poco más de $300 \mathrm{~m}$ de altitud (conocido como El Torreón) ubicado a no mucha distancia de donde confluyen los ríos Genal y Guadiaro, cumpliendo una clara función de control de esa vía natural de comunicación y de similar manera a como lo hace la no lejana Oba (Jimena de la Frontera), que le queda enfrente, dominando el valle del río Hozgarganta, afluente también del Guadiaro.

A esta ciudad antigua la nombran algunos autores clásicos como Plinio (Naturalis Historia, 3. 15: Blacippo), que indica su condición jurídica de ciudad estipendiaria en el conventus de Gades, Ptolomeo (2. 4. 9: $\Lambda \alpha \kappa \kappa \iota \pi \omega)$, que la incluye entre las poblaciones túrdulas de la Bética, y Pomponio Mela (Chorographia, 2. 94 s.) que la ubica en la vía de Malaca a Gades entre las mansiones de Salduba (alrededores de Marbella) y de Barbesula (desembocadura del río Guadiaro). Prueba de que era una ciudad indígena que hubo de pasar a la órbita de los romanos cuando estos llegaron a estas tierras del Mediodía peninsular a fines del siglo III a. de C. es el propio topónimo con

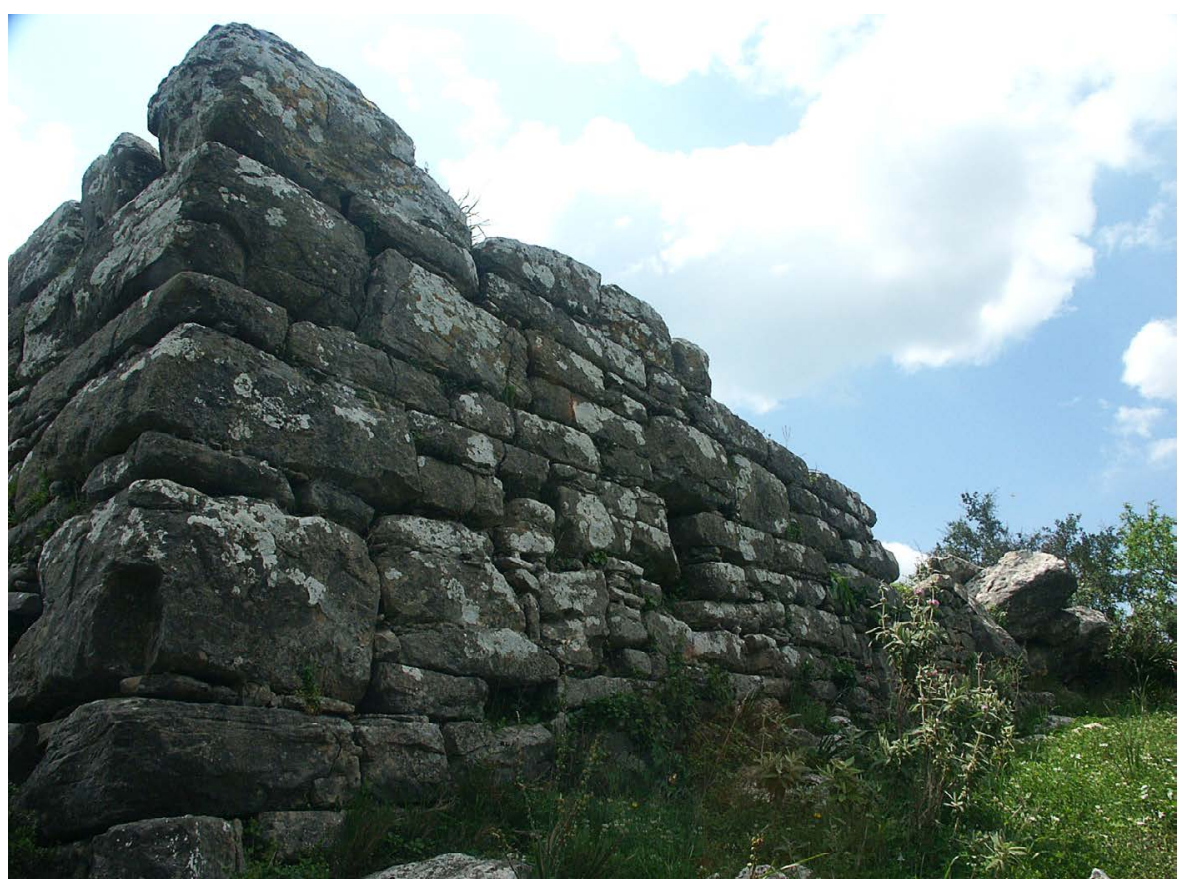


ese característico sufijo en -ipo/-ippo (que nada tiene que ver con el púnico hippo), que se ha interpretado como referencia al nombre "ciudad", "lugar habitado" (Villar Liébana) y que encontramos, entre otros muchos ejemplos, en las ciudades de Acinipo, Baesippo, Ventipo, Irippo, Ostippo...

Las primeras noticias sobre esas ruinas y algunas de las inscripciones allí encontradas las ofrece en 1663 el rondeño Macario Fariñas del Corral en su Tratado de las Marinas desde Málaga a Cádiz y algunos lugares sus vecinos según fueron en los siglos antiguos, manuscrito ${ }^{1}$ donde reproduce una carta de 1656 del erudito sevillano Félix Lasso de la Vega en la que dice que el "sitio que llaman hoy Alechipe... es un cerro descopetado, donde hay muchas ruinas de edificios que se tienden buen trecho a la falda hacia el septentrión. Allí hay manifiestas señales de unos antiguos baños. Dista este sitio poco más de un quarto de legua de Casares". De esas primeras noticias derivan las descripciones que de este despoblado antiguo y de algunos de sus epígrafes latinos hicieron varios autores del siglo XVIII, como el malagueño marqués de Valdeflores, el viajero inglés Francis Carter ( $A$ journey from Gibraltar to Malaga, II, London, 1772) o el canónigo de la catedral de Málaga Cristóbal de Medina Conde, quien en su manuscrito Antigüedades, y edificios suntuosos de la Ciudad, y Obispado de Málaga ${ }^{2}$ dice que el lugar "es un despoblado... al qe. Ilaman Alechipe qe. los unos pronuncian Chipre hay ruinas de poblaon. antigua romana, y entre ellas se han descubierto tres inscripciones suias de las qe. una es la... encajada en la pared del cortijo llamado Jerbonil qe. está al pie del cerro de Alechipe. Las otras dos se llevaron

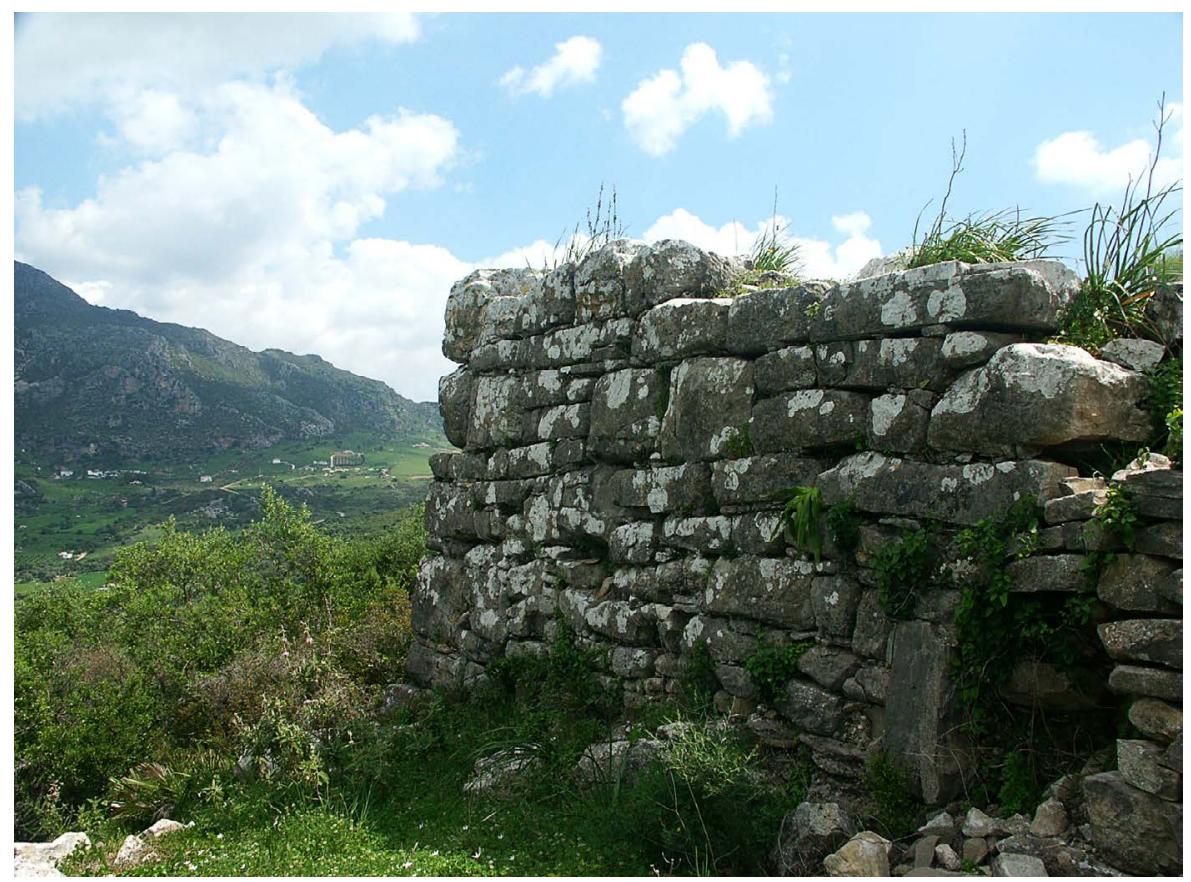

1

Ms. Real Academia de la Historia de Madrid, sig. 9/5.996, fols. 37 r. y v.; ms. Universidad de Sevilla. Colección Antonio Delgado y Hernández. Legajo 19. Varios. Sign. 2410, núm reg. 2411. Ed. facs. del ms. de la RAH por Ángel Caffarena, Málaga, 1965.

2

Ms. Biblioteca Nacional. Madrid núm. 10.451. Ed. facs. Universidad de Málaga, Málaga, 1992. 


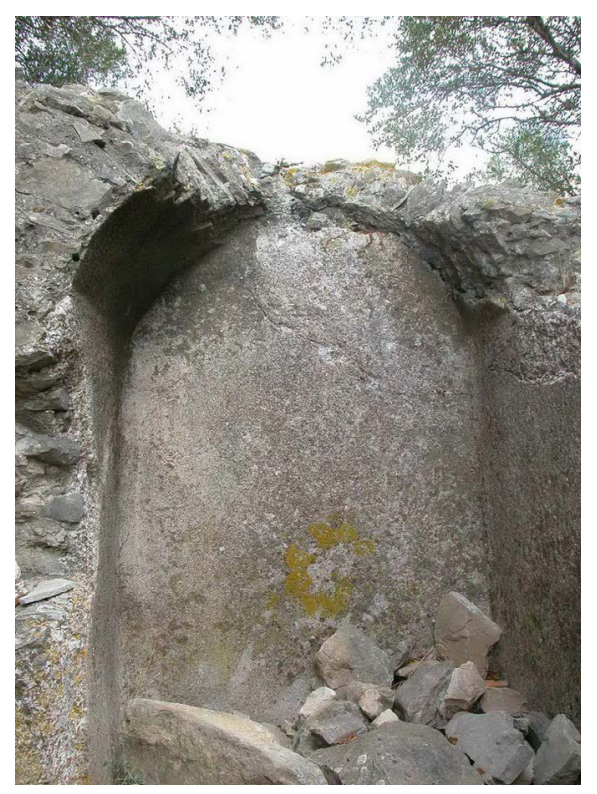

Detalle de las cisternas situadas junto a la ciudad foto Museo de Estepona (Ildefonso Navarro Luengo)

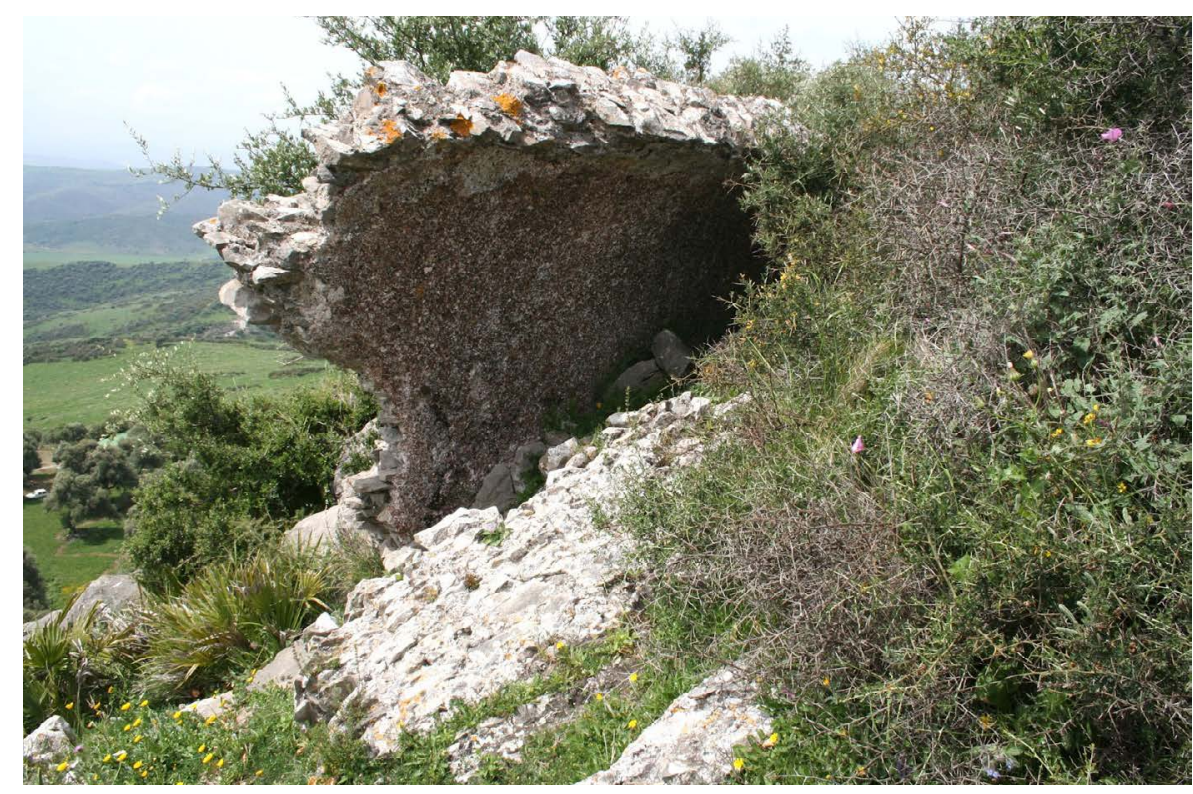

a Casares y... Laso de la Vega las vio a los dos lados de la puerta de Alonso del Río Chacón". Estas noticias son en líneas generales las mismas que ese autor ofrece en el tomo II de sus Conversaciones históricas malagueñas (1790). En la primera mitad del siglo XIX se repitieron esas mismas noticias y de ello puede ser ejemplo la breve descripción sobre "las ruinas de la antigua ciudad estipendiaria de Lacippo" que en 1832 ofreció Juan Agustín Ceán Bermúdez en el Sumario de las antigüedades romanas que hay en España. Recién traspasada la mitad de esa centuria, los tres únicos epígrafes latinos de esta ciudad antigua que hasta entonces se conocían fueron publicados de modo científico por el alemán Emil Hübner (CIL II 1934, 1935, 1936), primero en los Informes sobre el viaje epigráfico de España y Portugal que realizó en 1860-61 y que fueron editados por la Academia de Ciencias de Berlín, y luego en el volumen II del Corpus Inscriptionum Latinarum que recopilaba todas las inscripciones de las tres provincias romanas de Hispania conocidas hasta ese momento. Hübner describió a Lacipo como "un despoblado situado a orillas del rio Genal y que dista de Casares media legua... que ahora recibe el nombre de Alechipe" y de cuyas inscripciones y otros restos arqueológicos desde Casares le facilitó noticias don Juan Pérez de Vargas y Salas, "hombre amabilísimo", que le informó que en el lugar de Alechipe se conservaban "indicios ciertos de la ciudad antigua... como una piedra con una inscripción... además de que en el mismo sitio vio un busto masculino de mármol, sin duda obra romana... y, más tarde, se encontraron allí una cabeza femenina marmórea y también un bajorrelieve con la cabeza de un toro"3; además, le hizo llegar copia de dos de esas inscripciones que todavía se conservaban empotradas en la fachada de su casa familiar en Casares, la de los herederos de don Ignacio de Salas, así como el texto de una tercera 
(CIL II 1937) que el estudioso germano afirmaba en 1869 que su informante de Casares había visto en Alechipe "caída entre las piedras de la ciudad antigua". Ese don Juan Pérez de Vargas era el hermano del abuelo materno (Ignacio Pérez de Vargas) de quien habría de ser el más ilustre de los hijos de esa localidad malagueña y padre de la patria andaluza, Blas Infante Pérez de Vargas (1885-1936). Ha sido una referencia, repetida por muchos, que Blas Infante estuvo muy interesado en esas ruinas romanas, lugar que pudo visitar con asiduidad sobre todo entre 1901 y 1904, en que a sus quince años volvió a su pueblo natal al acabar en Archidona el bachillerato, y entre 1907-1909 cuando, finalizados sus estudios de Derecho en la Universidad de Granada, preparaba oposiciones a notarías de las que ganaría una plaza en Cantillana (Sevilla) para cuya toma de posesión hubo de esperar hasta cumplir la edad reglamentaria en 1910. Una noticia de 1933 indica (sin que esto se haya podido comprobar) que Blas Infante habría estado en Lacipo en el verano de 1932 descubriendo entre los vestigios de la ciudad "varias piedras labradas en relieve habiendo dejado cercado el sitio para hacer excavaciones"4. Interesado como era en toda clase de temas históricos, efectivamente, entre sus escritos inéditos se conservan hasta cuarenta y dos páginas referidas a Lacipo, y entre las fichas de la antigua Delegación Provincial de Excavaciones Arqueológicas, que se guardan en el archivo del Museo de Málaga, hay unas anotaciones de Giménez Reyna sobre las gestiones que en ese sentido se hicieron en 1952 ante su viuda que son buena prueba del desconocimiento que se tenía de Blas Infante por el silencio oficial que sobre él se impuso tras su asesinato en 1936. En la carta se afirmaba que Blas Infante era un "caído por Dios y por la Patria" y que "fue notario de Casares"5 Incluso, se ha supuesto que alguna de las pocas piezas arqueológicas que Blas Infante había reunido en su casa de Coria del Río pudiera tener su origen en esas actividades (J. Beltrán). Ciertamente, en aquella casa quedan (aparte unas hachas pulimentadas, un fragmento de borde de un cuenco cerámico y tres picos de ánforas romanas) una urna sepulcral de cerámica con su tapadera, pieza del siglo I d. de C., así como un capitel corintizante en mármol blanco con dos hojas de acanto contrapuestas en el kalathos y volutas y hélices decoradas con elementos vegetales propios del siglo II d.C., así como un fragmento del brazo izquierdo de una escultura en mármol blanco de época altoimperial que se cubría con un manto lleno de pliegues.

Entre las inscripciones latinas de esta ciudad antigua un grupo corresponde a dedicaciones públicas realizadas por la familia local de los Marcios; en una, Caio Marcio December testimonia que ha gastado setecientos cincuenta denarios en la estatua de la Fortuna Augusta que ha mandado colocar como agradecimiento a la curia por su elección como seviro y por haberle eximido del pago de la summa honoraria; otra de estas inscripciones daba cuenta de que Caio Marcio Cefalón al ser elegido por los duoviros locales como flamen del culto imperial donó cuatro mil sestercios; otro tercer epí-

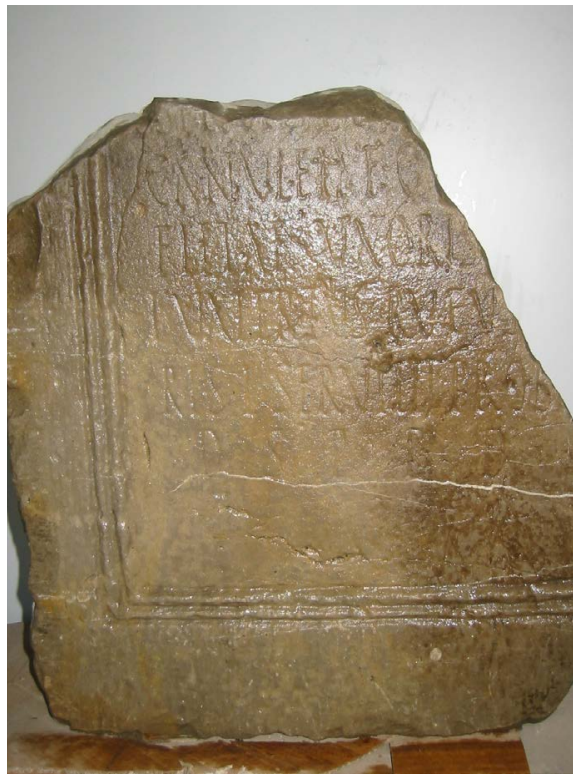

Pedestal con un epígrafe referido a una mujer de la gens Canuleia. Siglo I d. de C., actualmente en el Museo Municipal de San Roque, Cádiz | foto Margarita García Díaz

Biblioteca Cánovas del Castillo. Diputación Provincial de Málaga. Legado Juan Temboury. Sign. TEM_Doc_CSR_245_1.2.2.

Centro de Estudios Andaluces. Carta de 6 de octubre de 1952 de Simeón Giménez Reyna a la viuda de Blas Infante, doña Angustias García Parias, solicitándole datos sobre las investigaciones de su marido en la ciudad romana de Lacipo. 
Inscripción dedicada al Diuus Augustus por un quinqueviro y pontífice y en la que se mencionan dos elementos arquitectónicos del templo de culto imperia. Proceso de restauración. Lápida romana. Lacipo (Casares) | foto Fondo Gráfico IAPH

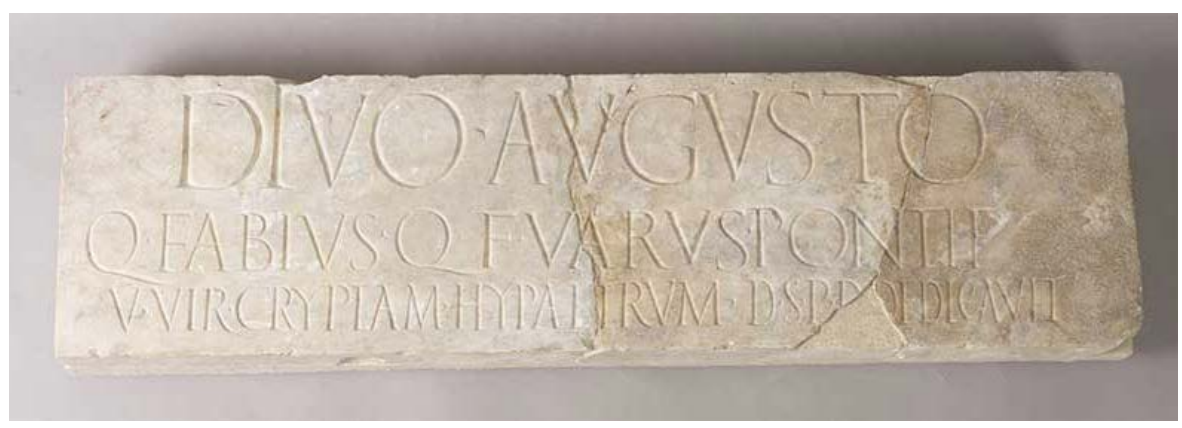

grafe, en fin, refería la dedicación de una estatua a la luventus Augusta que hizo Caio Marcio Niger con ocasión de su elección como flamen del culto de los emperadores. Precisamente a ese culto imperial, recién instituido tras la muerte de Augusto (14 d. de C.) en los comienzos del principado de su sucesor Tiberio, se refiere una interesante inscripción, hallada en 1975 durante la segunda campaña de excavaciones que hizo en el yacimiento Rafael Puertas, que lleva una dedicación al Divus Augustus por parte del quinquevir y pontifex Quinto Fabio Varo que mandó construir en el templo destinado al nuevo culto imperial una cripta, es decir, un criptopórtico y un hypaetrum, término semejante al de exareon con el que se designaba en esos edificios religiosos un espacio porticado y a cielo abierto (Fishwick). Sacerdote del culto a los emperadores (si es que la inscripción realmente es de Lacipo) fue también el Publio Valerio que hizo una dedicación a Mercurio como divinidad augustal, inscripción en un pedestal moldurado y parcialmente conservado que se guarda en el Museo de San Roque (Cádiz), como otro pedestal del mismo museo y traído desde Lacipo que tiene una dedicación a Lucio Servilio Probo y a su esposa Canuleia por su heredero Lucio Valerio Rufo. Cuando en 1898 el conocido arqueólogo francés Pierre Paris visitó las ruinas de Lacipo pudo ver allí otros epígrafes latinos, todos textos funerarios que permanecieron en tierras de uno de los cortijos vecinos a Lacipo hasta que en 1961 los transportó (junto a unos relieves de los que luego hablaremos) a las ruinas de Carteia (San Roque) el arqueólogo Martínez Santa Olalla de donde han pasado a su actual destino en los museos de San Roque y de Málaga. Una era una placa con un texto funerario referido a L. Aemilio Saturio y las otras, tres cubiertas de incineraciones talladas en bloques de caliza local, una en forma de cupa y las otras de tejado a dos aguas y de avanzado el siglo I d. de C., que llevan en su frente textos escasamente conservados sobre los allí enterrados, alguno con el gentilicio Canuleio, lo que evoca (junto a la Canuleia antes referida) la conocida página narrada por Tito Livio (Ab Urbe conditia, XLIII, 3, 1-4) de la deductio en 171 a. de C. por el pretor Lucio Canuleio de la Colonia Latina Libertinorum en la cercana Carteia y plantea unas relaciones hasta ahora desconocidas entre los antiguos colonos de esa ciudad de la bahía de Algeciras y la ciudad de Lacipo. 
De época republicana son algunos testimonios que indican que Lacipo tuvo una cierta importancia en los dos siglos anteriores al cambio de era. De destacar son sus acuñaciones, documentos difíciles de estudiar por su escasez y por la probable existencia de varias falsificaciones modernas. Al siglo I a. de $C$. hay que adscribir los pocos ejemplares que se conocen de sus semises, que llevan como tipos en su anverso un toro y sobre él un astro y en el reverso un delfín junto al nombre de la ciudad en alfabeto latino: LAC / IPO que, a veces, aparece escrito en forma retrógrada. Al haberse hallado algunas de estas monedas en el sitio de Alechipe se han usado (Mateos Gago) como prueba de la identificación de esas ruinas con la Lacipo citada en las fuentes. La presencia en ella de un emblema marítimo se ha venido interpretando como evidencia de su cercanía a la costa, aunque sus más que evidentes paralelos con las acuñaciones de Asido (Medina Sidonia) llevan a entender los símbolos del toro, el delfín y el astro más que como referencia geográfica o a un contexto económico como alusiones al mundo cultural y religioso púnico y en concreto a las divinidades Tanit y Baal-Hammon.

Si en fechas inmediatamente anteriores al cambio de era los abridores de cuño locales representaban en esas monedas tales tipos animalísticos, otras figuraciones zoomorfas de estilo semejante se encuentran en una serie de relieves sobre bloques de caliza local, con camas para grapas de unión de los diversos ortostatos y que debieron pertenecer a monumentos funerarios de tipo turriforme en las necrópolis de esta localidad. Corresponden al último período de la escultura ibérica, el que se viene denominando ibero-romano de entre los siglos III-I a. de C. Una pareja de estos relieves del Museo de Málaga representa sendos carneros de perfil, en movimiento y con un cierto detalle en el tratamiento de los vellones de su cuerpo y en la cabeza en la que destacan unos enroscados cuernos. Otro, que es pieza muy rodada y que ahora se conserva en los almacenes del museo de Cádiz, muestra una figura femenina en posición frontal, velada y que, como una orante o plañidera, lleva una de sus manos a su cintura y con la otra se toca la cara. Un último ejemplar representa un jinete cubierto con manto, armado con un gran escudo circular con umbo central y que lleva de las riendas un caballo al paso, tema alegórico quizá de la victoria del héroe sobre la muerte en la ultratumba.

Las laderas del monte donde se alzan las ruinas de la ciudad de Lacipo no ofrecen en todos sus lados la suficiente pendiente y dificultad de accesibilidad para una defensa natural lo que ha obligado a la construcción en varias zonas de un recinto amurallado de evidente carácter defensivo, bien adaptado al terreno y formado en la parte más antigua por grandes bloques de caliza unidos en seco, escuadrados y rudamente careados. En el caso del lado meridional, sobre aquella muralla ciclópea se construyó en época imperial otra de mampostería de la que queda un gran lienzo de algo más de 3 metros de altura y unos 7 de longitud. Al pie de la ladera suroriental quedan

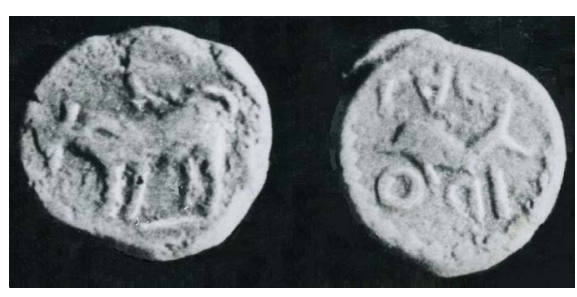

Semis de la ceca de Lacipo, según Antonio Vives y Escudero en La moneda hispánica, Madrid 1924 lám. 120
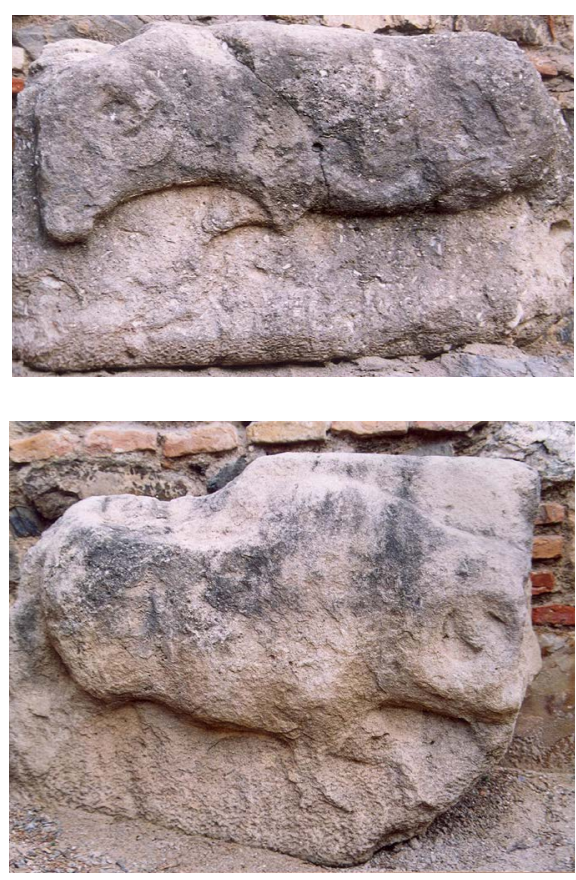

Relieves ibero-romanos con representaciones de carneros de una de las necrópolis

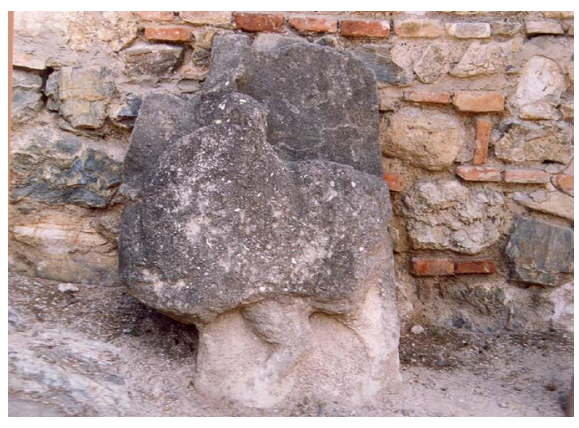

Relieve ibero-romano de monumento funerario (relieves acutalmente conservados en el Museo de Málaga) | fotos Pedro Rodríguez Oliva 


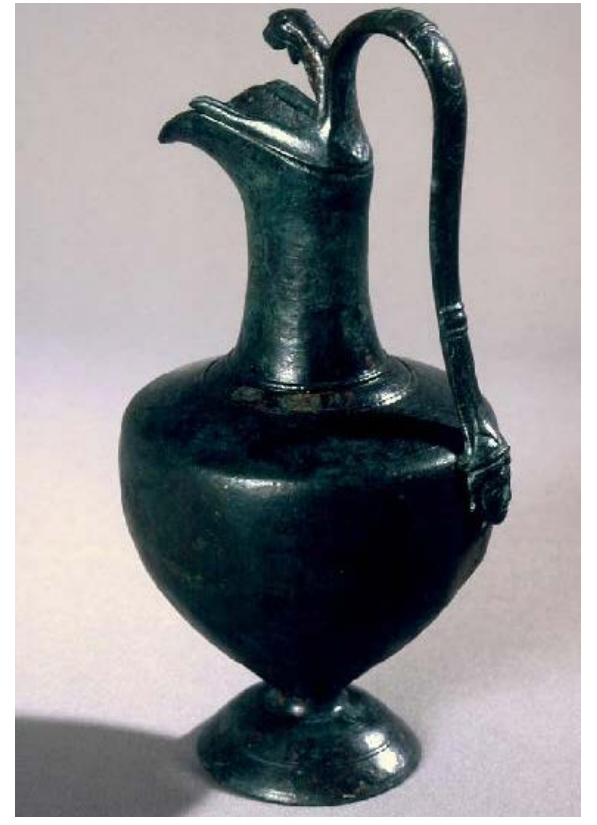

Praefericulum en bronce hallado en Lacipo | foto Museo de Málaga

\section{6}

Varias fotos de los relieves iberromanos de Lacipo, de González Edo, se conservan en el Legado Temboury en la Biblioteca Provincial de Málaga y, en el Archivo Histórico Provincial malagueño hay unas cartas de 1960 (Sección D. J. González Edo. Lejajo 14-004.P. 13) cruzadas entre este arquitecto y el vecino de Marbella D. Henry G. Joarlette, que decía haber sido muy aficionada a la arqueología en el Marruecos francés y que le solicitaba datos de la lejana visita de Gonzáles Edo al yacimiento que decía haber recorrido en septiembre de 1959 junto a Luis Barrionuevo, el corresponsal en Málaga del diario ABC.

7

CIL II2/7, 259 restos bien conservados de tres cisternas de unos $5 \mathrm{~m}$ de lado, cubiertas con bóvedas de medio cañón, con escalones para bajar a su fondo e impermeabilizado su interior con un fuerte revestimiento hidráulico de opus signinum. Dos de ellas aparecen comunicadas entre sí por una abertura en la pared y hay restos de una cuarta muy ruinosa.

Aunque en las construcciones domésticas más antiguas se documentan cisternas subterráneas, en época imperial la ciudad se dotó para el consumo de estos receptáculos hidráulicos hasta los que llegaba el agua a través de un acueducto que arrancaba del manantial de la Fuente Grande o Fuente Santa en la cara sureste y a media ladera de la elevada sierra Crestellina, junto a Casares, y que a través de una conducción en parte subterránea y en parte al aire libre sobre pilae rectangulares discurría durante unos 4 kilómetros hasta llegar a las cisternas ubicadas al pie del monte Torrejón o Pellizcoso donde se emplaza la ciudad. De la canalización de esas aguas por la zona monumental debió surtirse una estatua fuente en mármol blanco que representaba un Dionysos u otro personaje de su thyasos sedente y con un vaso en sus manos del que manaba el líquido y de la que unos fragmentos se conservan en el Ayuntamiento de Casares.

También se dice que procede de Lacipo un fragmento de la cara de una escultura de la The Hollander Collection de Aspen (Colorado, USA) y una mano asiendo un ropaje, fragmento perdido de otra estatua marmórea, que fotografió el arquitecto José Joaquín González Edo (1894-1989) que en 1934 visitó esas ruinas con motivo de la redacción de un proyecto de escuela rural en el partido de Alechipe que finalmente no se llegó a construir $^{6}$. Restos arqueológicos estos de la Lacipo altoimperial que, al igual que los numerosos epígrafes antes mencionados o los abundantes materiales hallados en las excavaciones realizadas en el yacimiento en 1975 y 1976 que se exponen en el Museo de Málaga, evidencian la importancia de este núcleo urbano del Conventus de Gades también en los siglos I y II d. de C. e, incluso, en la siguiente centuria a cuyo comedio corresponde el pedestal de una estatua hallado en Córdoba con un epígrafe ${ }^{7}$ referido al laciponense Marco Valerio Saturnino, que en esa capital de la Baetica ejerció la función de flamen provincial. Lo hasta ahora conocido de Lacipo evidencia un lugar en plena decadencia durante la Antigüedad Tardía que no tuvo continuidad tras la llegada de los árabes a comienzos del siglo VIII. 


\section{BIBLIOGRAFÍA}

- BELTRÁN FORTES, J.; ESCACENA CARRASCO, J. L. (2004) Piezas arqueológicas: La búsqueda de los orígenes. EGEA, A. (coord.) La Casa de Blas Infante en Coria del Río. Sevilla: Centro de Estudios Andaluces, 2004, pp. $61-73$

- BELTRÁN FORTES, J. ; RODRÍGUEZ OLIVA, P. (2008) Arqueología de Andalucía: Algunos ejemplos de actividades arqueológicas en la primera mitad del siglo XX. En BELTRÁN FORTES, J.; HABIBI, M. (ed.) Historia de la Arqueología en el Norte de Marruecos durante el período del Protectorado y sus referentes en España. Sevilla: Universidad, 2008, pp. 63-95

- Compaña PRIETO, J. M.; CARO heRRERO, J. L. (2016) Moneda falsa, retocada e inventada en la numismática malagueña. Actas XV Congreso Nacional de Numismática, Madrid, 2014 (Patrimonio numismático y museos). Madrid, 2016, pp. 629-642

- CORZO SÁNCHEZ, S. (2005) La ceca romana de Lacipo: Análisis y nuevo hallazgo. Actas XIII Congreso Internacional de Numismática (Madrid, 2003), vol. 1. Madrid, 2005, pp. 499-502

- DECRETO 59/1996, de 6 de febrero, por el que se declara Bien de Interés Cultural, con la categoría de Zona Arqueológica, el yacimiento denominado Ciudad Romana de Lacipo, en el término municipal de Casares (Málaga). $B O J A$, n. ${ }^{\circ} 74$, de 29 de junio de 1996, pp. 7005-7007; BOE n. ${ }^{\circ} 172$ de 17 de julio de 1996, pp. 22636-7

- ETIENNE, R. (1981) Culte impérial et architecture: À propos d'une inscription de Lacipo (Bétique). ZPE 43 (1981), pp. 135-142

- MORA SERRANO, B. (1990) Málaca, Acinipo y Lacipo: tres cecas monetales en los territorios malacitanos. Jábega. Revista de la Diputación Provincial de Málaga, 67 (1990), pp. 3-12

- NAVARRO LUENGO, I. (2005) El abastecimiento de agua a una ciudad romana: Lacipo (Casares). Aqua Nostra. Agua de todos. El agua en la Costa Occidental malagueña, Asociación Cilniana de Marbella, Málaga, 2005, pp. 99-102

- PUERTAS TRICAS, R. (1979) Nuevo epígrafe monumental de Lacipo. Mainake 1, 1979, pp. 99-104

- PUERTAS TRICAS, R. (1982) Excavaciones arqueológicas en Lacipo (Casares, Málaga). Campañas de 1975 y 1976. Excavaciones Arqueológicas en España, n. ${ }^{\circ}$. 123, Madrid, 1982

- PUERTAS TRICAS, R; RODRÍGUEZ OLIVA, P. (1980)

Estudios sobre la ciudad romana de Lacipo. Studia Archaeologica, 64, Valladolid, 1980

- RODRíguez OLIVA, P. (1976) Una estatua-fuente de Lacipo. Jábega. Revista de la Diputación Provincial de
Málaga 13 (1976), pp. 43-46

- RODRíguez OLIVA, P. (2001-2002) Sobre las esculturas ibéricas e ibero-romanas de los territorios malacitanos. Anales de Prehistoria y Arqueología. Universidad de Murcia, 16-17 (Homenaje al Dr. Emeterio Cuadrado in memoriam) (2001-2002), pp. 467-485

- RODRÍGUEZ OLIVA, P. (2003) Esculturas zoomorfas de época de época romano-republicana de la provincia de Málaga. Mainake, XXV, 2003, pp. 321-357

- RODRíguez OLIVA, P. (2006) Unas inscripciones funerarias de Lacipo (Casares, Málaga) que evocan el establecimiento en Carteia (San Roque, Cádiz) de la Colonia Latina Libertinorum. Baetica 28/2 (2006), pp. 123158

- RODRÍGUEZ OLIVA, P. (2006) Investigaciones arqueológicas en Lacipo (Casares, Málaga). En I Jornadas sobre Patrimonio de Casares. Málaga: Ayuntamiento de Casares; Centro de Ediciones de la Diputación Provincial de Málaga, 2006, pp. 299-327

- RODRíGUEZ OlIVA, P.; PUERTAS TRICAS, R. (1979) La ciudad de Lacipo y sus monedas. Mainake 1 , 1979, pp. 105-127

- SOTO JIMÉNEZ Y ARANAZ, L. (1979) Lacipo, ciudad turdetana y romana. Jábega. Revista de la Diputación Provincial de Málaga, 28, 1979, pp. 3-7 